

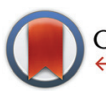

CrossMark \& click for updates

Cite this: Dalton Trans., 2016, 45 5958

Received 12th October 2015, Accepted 30th October 2015

DOI: $10.1039 / c 5 d t 03996 \mathrm{~g}$

www.rsc.org/dalton

\title{
Smallest molecular chalcogenidometalate anions of the heaviest metals: syntheses, structures, and their interconversion $\uparrow$
}

\author{
G. Thiele, C. Donsbach, R. Riedel, M. Marsch, K. Harms and S. Dehnen*
}

The syntheses of the first molecular meta-selenidomercurate(॥), ortho-telluridothallate(॥I) and a hydrate of an ortho-selenidoplubate(Iv) are presented alongside an improved and facile synthesis of the selenidobismuthate(III) with almost quantitative yields. By means of quantum chemical calculations, the energetics of the interconversions of small metalate anions is discussed and the existence of the heaviest homologues of $\left[\mathrm{NO}_{2}\right]^{-},\left[\mathrm{NO}_{3}\right]^{-},\left[\mathrm{PO}_{4}\right]^{2-}$ and $\left[\mathrm{CO}_{3}\right]^{2-}$ are predicted.

\section{Introduction}

Chalcogenides of the heavy metals possess intriguing optoelectronic $^{1}$ and thermo-electric ${ }^{2}$ properties and have therefore been used in numerous applications. ${ }^{3}$ Those properties can be fine-tuned and adjusted via dimensional reduction, ${ }^{4}$ the choice of elemental combination, ${ }^{5}$ or further incorporation of additional metal species towards multinary compounds. ${ }^{6}$ Conventional solid state syntheses, solvothermal reaction pathways and solution-based methods have been shown to facilitate the generation of a large variety of such compounds, including chalcogenidometalate salts. ${ }^{7}$

Whereas the class of oxidometalates has extensively been studied - regarding both their fundamental properties and their potential applications - only a few reports have been dealing with the elemental combination of atoms of the heaviest metals with heavier chalcogen ligands. Here, we will concentrate on salts of the smallest of the heaviest chalcogenidometalate anions, hence with the general formulae $\left[\mathrm{M}_{x} \mathrm{Ch}_{y}\right]^{z-}(\mathrm{M}=\mathrm{Hg}, \mathrm{Tl}, \mathrm{Pb}, \mathrm{Bi} ; x=1$ or 2 ; $\mathrm{Ch}=\mathrm{Se}$ or $\mathrm{Te}, y=$ $2-4$ ), of which only the following are known to date. Besides the mononuclear ortho-chalcogenidomercurate anion $\left[\mathrm{HgCh}_{4}\right]^{6-}$, received from solid state reactions, ${ }^{8}$ only the linear $\left[\mathrm{HgCh}_{2}\right]^{2-}$ anion, synthesized in solution, ${ }^{9}$ has been reported thus far. Molecular chalcogenidothallates and chalcogenidoplumbates have only been obtained from solution. Molecular chalcogenidothallates have so far been restricted to Schrobil-

Philipps-Universität Marburg, Fachbereich Chemie and Wissenschaftliches Zentrum für Materialwissenschaften, Hans-Meerwein-Straße 4, D-35043 Marburg, Germany. E-mail: dehnen@chemie.uni-marburg.de; Fax: +49 6421282 5653;

Tel: +4964212825751

$\dagger$ Electronic supplementary information (ESI) available. CCDC 1430781-1430790. For ESI and crystallographic data in CIF or other electronic format see DOI: $10.1039 / \mathrm{c} 5 \mathrm{dt} 03996 \mathrm{~g}$ gen's dinuclear $\left[\mathrm{Tl}_{2} \mathrm{Te}_{2}\right]^{2-} \cdot{ }^{10}$ The largest number of small anions is currently found among the chalcogenidoplumbates. Here, one knows the ortho-selenidoplumbate anion $\left[\mathrm{PbSe}_{4}\right]^{4-}, 11$ the dinuclear, trigonal bipyramidal $\left[\mathrm{Pb}_{2} \mathrm{Ch}_{3}\right]^{2-}$ anion, ${ }^{12}$ and the mononuclear trigonal pyramidal species $\left[\mathrm{PbTe}_{3}\right]^{4-} \cdot{ }^{13}$ For bismuthates, only the trigonal pyramidal $\left[\mathrm{BiCh}_{3}\right]^{3-}$ is known from solid state $^{14}$ and solution-based approaches. ${ }^{15}$

Based on a broad experience in chalcogenidogermanate and chalcogenidostannate chemistry, ${ }^{16}$ we are currently about to extend the investigations on the heaviest tetrel congener as well as related anions of the neighbouring heavy metal elements. For this, we are addressing the synthesis of new small and soluble metalate anions, besides the exploration of their physical properties as well as their reactivity in solution or under solvothermal conditions. During the course of our investigations, we were able to synthesize a number of according compounds comprising new such anions with unprecedented elemental combinations, and were thus interested in general tendencies of the energetics of such species and their hypothetical interconversion. Here we report about our findings for the first time.

\section{Experimental and computational details}

\subsection{General remarks and synthesis details}

All manipulations and reactions were performed in an argon atmosphere using standard Schlenk or glovebox techniques under strict exclusion of air and external moisture. Multinary solid mixtures of the nominal parent composition " $\mathrm{A}_{\mathrm{m}} \mathrm{A}_{\mathrm{n}}^{\prime} \mathrm{M}_{\mathrm{o}} \mathrm{M}_{\mathrm{p}}^{\prime} \mathrm{Ch}_{\mathrm{q}}$ " (A, K; $\mathrm{A}^{\prime}=\mathrm{Na} ; \mathrm{M}=\mathrm{Hg}, \mathrm{Tl}, \mathrm{Bi} ; \mathrm{M}^{\prime}=\mathrm{Pb} ; \mathrm{Ch}=$ $\mathrm{Se}, \mathrm{Te}$ ) were prepared by fusion of the elements and $\mathrm{K}_{2} \mathrm{Ch}$, 
unless stated otherwise, with an oxygen/methane burner for at least 15 min until homogeneity was achieved. The $\mathrm{m}: \mathrm{n}: \mathrm{o}: \mathrm{p}$ : $\mathrm{q}$ ratios, which are specified in the Discussion section, are those that actually produced the named products, usually after testing a variety of different ratios. If necessary, metallic byproducts were manually removed. The multinary product was pestled and further worked-up as described below. Solvents ethane-1,2-diamine (en), $N, N$-dimethylformamide (DMF) and pyridine were freshly distilled from $\mathrm{CaH}_{2}, \mathrm{H}_{2} \mathrm{O}$ was degassed at least three times to a final pressure of $p<10^{-5}$ mbar and successively saturated with argon atmosphere. $\mathrm{K}_{2} \mathrm{Ch}$ was synthesized from the elements in liquid $\mathrm{NH}_{3}$. Metal salts were evacuated to $p<10^{-3}$ mbar for at least $8 \mathrm{~h}$ unless otherwise noted.

In the case of solvothermal reaction conditions, the reactants and $2 \mathrm{~mL}$ of a chosen solvent were placed in a glass vial within a Teflon inlay which was then placed in a stainless steel autoclave. The autoclave has been tightly closed and heated to $150{ }^{\circ} \mathrm{C}(\mathrm{Ch}=\mathrm{Se})$ or to $130{ }^{\circ} \mathrm{C}(\mathrm{Ch}=\mathrm{Te})$ for 7 days and was allowed to slowly cool down to room temperature over 1 day. The products were hand-selected under a light microscope unless stated otherwise. The product mixture for the synthesis of thallate and plumbate compounds always contained amorphous (side-)products that were not further investigated, and $\mathrm{K}_{2} \mathrm{Ch}_{2}$ and $\mathrm{K}_{2} \mathrm{Ch}_{3}$ that were identified via single crystal diffraction. Consequently, the provision of yields is afflicted with high uncertainty. Energy dispersive X-ray spectroscopy was performed on all samples to verify the given heavy atom composition. All yields are given with respect to the heaviest element involved in the respective case.

Synthesis of $\mathbf{K}_{4}\left[\mathrm{HgSe}_{3}\right] \cdot \mathbf{H}_{2} \mathbf{O}$ (1). $0.8 \mathrm{~g}$ (5.1 mmol, $3 \mathrm{eq}$.) of $\mathrm{K}_{2} \mathrm{Se}, 0.5 \mathrm{~g}$ (1.7 mmol, 1 eq.) of $\mathrm{HgSO}_{4}$ and $2 \mathrm{~mL}$ of en were treated according to the solvothermal reaction protocol. 1 was obtained as yellow blocks in approx. $80 \%$ yield beside $\mathrm{K}_{2} \mathrm{SO}_{4}$.

Synthesis of $\mathrm{K}_{4}\left[\mathrm{HgTe}_{3}\right] \cdot \mathrm{H}_{2} \mathrm{O}$ (2). $2.10 \mathrm{~g}$ (10.2 mmol, 3 eq.) of $\mathrm{K}_{2} \mathrm{Te}, 1 \mathrm{~g}$ (3.4 mmol, 1 eq.) of $\mathrm{HgSO}_{4}$ and $2 \mathrm{~mL}$ of en were treated according to the solvothermal reaction protocol. 2 was obtained as metallic black blocks in approx. 20\% yield beside $\mathrm{K}_{2} \mathrm{SO}_{4}$ and polytellurides.

Synthesis of $\mathrm{K}_{10} \mathrm{Na}_{2}\left[\mathrm{HgTe}_{3}\right]_{2}\left(\mathrm{HCO}_{2}\right)_{3}$ (3). $1 \mathrm{~g}$ of a phase of the nominal composition $\mathrm{K}_{3} \mathrm{NaHgTe}_{3}$ and $2 \mathrm{~mL}$ of DMF were treated according to the solvothermal reaction protocol. A few crystals of 3 were obtained as metallic black blocks.

Synthesis of $\mathrm{K}_{2}\left[\mathrm{HgSe}_{2}\right] \cdot \mathrm{H}_{2} \mathrm{O}$ (4). $0.5 \mathrm{~g}$ of a phase of the nominal composition $\mathrm{K}_{2} \mathrm{HgPbSe} \mathrm{P}_{2}$ and $2 \mathrm{~mL}$ of pyridine with $0.5 \mathrm{vol} \%$ of $\mathrm{H}_{2} \mathrm{O}$ were treated according to the solvothermal reaction protocol. 4 was obtained as orange blocks in approx. $30 \%$ yield.

Synthesis of $\mathbf{K}_{6}\left[\mathrm{Tl}_{2} \mathrm{Se}_{6}\right] \cdot 2 \mathrm{H}_{2} \mathrm{O}$ (5). $0.5 \mathrm{~g}$ of a phase of the nominal composition $\mathrm{K}_{5} \mathrm{TlSe}_{4}$ and $2 \mathrm{~mL}$ of en with $0.5 \mathrm{vol} \%$ of $\mathrm{H}_{2} \mathrm{O}$ were treated according to the solvothermal reaction protocol. 5 was obtained as red plates in approx. $15 \%$ yield.

Synthesis of $\mathrm{K}_{6}\left[\mathrm{Tl}_{2} \mathrm{Se}_{6}\right] \cdot 2 \mathrm{~K}_{2} \mathrm{CO}_{3}(6) .0 .5 \mathrm{~g}$ of a phase of the nominal composition $\mathrm{K}_{5} \mathrm{TlSe}_{4}, 0.05 \mathrm{~g}$ of $\mathrm{K}_{2} \mathrm{CO}_{3}$ and $2 \mathrm{~mL}$ of en were treated according to the solvothermal reaction protocol. A few crystals of 6 were obtained as orange blocks.
Synthesis of $\mathbf{K}_{\mathbf{0 . 9 4}} \mathbf{T l}_{\mathbf{0 . 0 6}}\left[\mathrm{TlSe}_{2}\right]$ (7). $0.5 \mathrm{~g}$ of a phase of the nominal composition $\mathrm{K}_{2} \mathrm{TlSe}_{2}$ and $2 \mathrm{~mL}$ of en were treated according to the solvothermal reaction protocol. 7 crystallizes as black blocks beside $\mathrm{Tl}\left[\mathrm{TlSe}_{2}\right], \mathrm{K}_{2} \mathrm{Se}_{2}$ and $\mathrm{K}_{2} \mathrm{Se}_{3}$.

Synthesis of $\left\{\mathrm{K}_{5}\left[\mathrm{TlTe}_{4}\right] \cdot 2 \mathrm{KOH}\right\}_{3} \cdot \mathbf{1 0 H}_{2} \mathrm{O}(8) .1 \mathrm{~g}$ of a phase of the nominal composition KTlTe and $2 \mathrm{~mL}$ of en with 3 vol\% of $\mathrm{H}_{2} \mathrm{O}$ were treated according to the solvothermal reaction protocol. 8 was obtained as black blocks in approx. 15\% yield beside several known polytelluride salts.

Synthesis of $\mathbf{K}_{4}\left[\mathrm{PbSe}_{4}\right] \cdot \mathbf{e n} \cdot \mathrm{H}_{2} \mathrm{O}$ (9). $0.5 \mathrm{~g}$ of a phase of the nominal composition $\mathrm{K}_{2} \mathrm{HgPbSe} \mathrm{P}_{2}$ and $2 \mathrm{~mL}$ of en with $0.5 \mathrm{vol} \%$ of $\mathrm{H}_{2} \mathrm{O}$ were treated according to the solvothermal reaction protocol. 9 was obtained as red blocks in approx. $20 \%$ yield.

Synthesis of $\mathrm{K}_{3} \mathrm{BiSe}_{3}(\mathbf{1 0})$. A phase of the nominal composition $\mathrm{K}_{3} \mathrm{BiSe}_{3}$ was washed with en until no coloured contaminants were observable any more. 10 was obtained in up to $90 \%$ yield as orange microcrystalline powder. Crystals suitable for single crystal diffraction were obtained via recrystallization according to the solvothermal reaction protocol in $2 \mathrm{~mL}$ of en.

\subsection{General computational details}

All molecular electronic structure calculations were carried out with the TURBOMOLE program package V6.6. ${ }^{17}$ COSMO was used for the compensation of negative charges, applying the default parameters with $\varepsilon=\infty .{ }^{18}$ Structure optimizations were undertaken by employment of the RIDFT program, using the BP86 functional ${ }^{19}$ and def2-TZVP basis sets with respective ECPs. $^{20}$ The optimized structures were confirmed to be local minima on the energy hypersurface by means of calculations of the $2^{\text {nd }}$ derivative of the energy. Further details are given in the ESI. $\dagger$

\section{Results and discussion}

Our primary objective was the synthesis and characterization of small and heavy chalcogenidometalate homologues of their lighter congeners, e.g. stannates or indates. ${ }^{21}$ We therefore systematically investigated solvothermal reactions of phases of the nominal composition " $\mathrm{A}_{x} \mathrm{M}_{y} \mathrm{Ch}_{z}$ " (A = alkali(ne earth) metal, $\mathrm{M}=\mathrm{Hg}, \mathrm{Tl}, \mathrm{Pb}, \mathrm{Bi}$; $\mathrm{Ch}=\mathrm{Se}, \mathrm{Te})$, in most cases with $x: y: z$ such that the ratio corresponds with a charge balance for ortho-metalates $(x: 1: 4)$ or meta-metalates $(x: 1: 3)$. We started out with selenium as the chalcogen component, since according phases are generally thermally more stable and less sensitive. Upon identification of suitable reaction conditions for the selenium containing compounds, analogous reactions were attempted with tellurium phases. Due to the lower thermal stability of the latter, the reaction temperatures were then decrease by at least $20^{\circ} \mathrm{C}$, and the amount of starting materials was increased by a factor of two or more due to higher solubility.

The phases were then treated under solvothermal reaction conditions with diverse solvents, such as amines, alcohols, thiols and ethers. Until now, only the application of amines yielded products that were suitable for single crystal diffraction 
experiments, apart from the formation of a vast variety of single-crystalline polyselenides from other solvents. ${ }^{22,23}$

We also tested whether water, amines like $\mathrm{NH}_{3}, 2,6-\mathrm{di}$ methylmorpholine (dmmp) or 4-(dimethylamino)pyridine (dmap), ammonium or phosphonium salts $\left(\mathrm{NMe}_{4} \mathrm{Cl}, \mathrm{NBu}_{4} \mathrm{Cl}\right.$, $\mathrm{PPh}_{4} \mathrm{Cl}$ ), or Brønstedt bases $\left(\mathrm{AOH}, \mathrm{A}_{2} \mathrm{CO}_{3}\right)$ might serve as auxiliary reactants for enhanced hydrogen bonding, and/or to change the basicity. However, only addition of water, or (in reactions of thallium compounds) addition of Brønstedt bases led to the formation of crystalline products (see below).

Upon solvothermal treatment of phases that contained mercury as $\mathrm{K}_{x} \mathrm{Hg}_{y} \mathrm{Se}_{z}$ (with all combinations of $x=2-6, y=$ $1-10, z=1-12$ ), we exclusively observed the formation of known compounds $\mathrm{K}_{2} \mathrm{Hg}_{3} \mathrm{Se}_{4},{ }^{24} \mathrm{~K}_{2} \mathrm{Hg}_{2} \mathrm{Se}_{3},{ }^{25}$ and polyselenides. ${ }^{22}$ We thus changed the mixture of starting materials to potassium monochalcogenides, $\mathrm{K}_{2} \mathrm{Ch}$, and mercury salts. This way, we crystallized $\mathrm{K}_{4}\left[\mathrm{HgSe}{ }_{3}\right] \cdot \mathrm{H}_{2} \mathrm{O}$ (1) or $\mathrm{K}_{4}\left[\mathrm{HgTe}_{3}\right] \cdot \mathrm{H}_{2} \mathrm{O}$ (2) upon utilization of $\mathrm{K}_{2} \mathrm{Ch}$ and $\mathrm{HgSO}_{4} \cdot n \mathrm{H}_{2} \mathrm{O}(0.1-n-2.7$ according to Karl Fischer titrations) in en as a solvent. The reaction towards the molecular meta-mercurate $\mathbf{1}$ is straight forward, according to a reaction scheme given in eqn (1):

$$
3 \mathrm{~K}_{2} \mathrm{Se}+\mathrm{HgSO}_{4}+\mathrm{H}_{2} \mathrm{O} \rightarrow \mathrm{K}_{4}\left[\mathrm{HgSe}_{3}\right] \cdot \mathrm{H}_{2} \mathrm{O}(\mathbf{1})+\mathrm{K}_{2} \mathrm{SO}_{4}
$$

The precipitation of $\mathrm{K}_{2} \mathrm{SO}_{4}$ seems to be the driving force, leading to an almost quantitative yield. Furthermore, the reaction can be scaled-up to $25 \mathrm{~g}$ per batch, only restricted by the volume of the glass vial within the autoclave. Solvent water in 1 stem from the crystal water in $\mathrm{HgSO}_{4} \cdot n \mathrm{H}_{2} \mathrm{O}$. The use of dried $\mathrm{HgSO}_{4}(n=0)$ results in the precipitation of a yellow amorphous powder, which can, however, be recrystallized in the presence of water to yield $\mathbf{1}$. The amount of crystal water in $\mathrm{HgSO}_{4} \cdot n \mathrm{H}_{2} \mathrm{O}$ varies with the time of storage from newly purchased $(n \approx 0.1$ ) to years of storage under ambient conditions and use $(n \approx 2.7)$.

The synthesis of the homologous meta-telluridomercurate $\mathrm{K}_{4}\left[\mathrm{HgTe}_{3}\right] \cdot \mathrm{H}_{2} \mathrm{O} 2$ can be carried out with the quoted, typical variations for a replacement of Se with Te: treatment of $\mathrm{K}_{2} \mathrm{Te}$ and $\mathrm{HgSO}_{4} \cdot n \mathrm{H}_{2} \mathrm{O}$ in en under solvothermal reaction conditions at slightly reduced temperature $\left(130{ }^{\circ} \mathrm{C}\right)$. However, the yields are lower, since $\mathrm{K}_{2} \mathrm{Te}_{2},{ }^{26} \mathrm{~K}_{2} \mathrm{Te}_{3},{ }^{27}$ and amorphous side products are obtained along with 2 . Intending to increase both yield and purity, we changed the reaction conditions to the use of a solid mixture containing sodium besides potassium. This way, we thought to allow for more flexibility in crystallization conditions according to various ionic radii. Further, we used DMF as solvent, as it is known that $\left[\mathrm{Na}(\mathrm{dmf})_{6}\right]^{+}$cations are easily formed and well soluble. However, in the present case, not 2 or its sodium salt was formed, but the meta-telluridomercurate $\mathrm{K}_{10} \mathrm{Na}_{2}\left[\mathrm{HgTe}_{3}\right]_{2}\left(\mathrm{HCO}_{2}\right)_{3}$ (3). 3 comprises a formiate moiety and $\mathrm{Na}^{+}$as well as $\mathrm{K}^{+}$counter ions. The formation of sodium formiate is often observed as a by-product due to decomposition of DMF under the given conditions; for this, the presence of the additional anion was not unexpected.

With a solvothermal reactions starting from a phase of the nominal composition $\mathrm{K}_{2} \mathrm{PbHgSe}_{2}$ and pyridine as solvent, we investigated whether we might access a mixture of metalate anions, either in a double salt or a salt of a ternary anion, or not. The latter turned out to be the case, as small amounts of $\mathrm{K}_{2}\left[\mathrm{HgSe}_{2}\right] \cdot \mathrm{H}_{2} \mathrm{O}$ (4) emerged from the experiment upon addition of $0.5 \mathrm{vol} \%$ of water to the reaction mixture. Complete absence of water, or other volume ratios than 995: 5 led to no or lower yields.

For us, such hydrate compounds are particularly interesting for their apparent stability in water and thus the potential for subsequent reactions in aqueous media, which are, however, beyond the scope of this report.

The crystallization of the hydrate $\mathbf{4}$ inspired us to revisit the formation of heavy main-group ortho-chalcogenidometalates, which have either not been identified at all (Tl, Bi) or at extremely low yields $(\mathrm{Pb})^{11}$ to date. Upon solvothermal treatment of a phase of the nominal composition $\mathrm{K}_{5} \mathrm{TlSe}_{4}$ and en $/ \mathrm{H}_{2} \mathrm{O}$ as solvent, $\mathrm{K}_{6}\left[\mathrm{Tl}_{2} \mathrm{Se}_{6}\right] \cdot 2 \mathrm{H}_{2} \mathrm{O}(5)$ has been obtained. The formation of such dinuclear species was reported previously for some indates to be dependent on various reaction parameters, including the $\mathrm{pH}$ value. ${ }^{6,21,28}$ We thus explored the utilization of different amines, addition of various amounts of $\mathrm{NH}_{3}$ or $\mathrm{H}_{2} \mathrm{O}$, and Brønstedt bases. However, for the heavier congener of indium, none of these variations yielded the mononuclear ortho-selenidothallate. Additional change of the nominal composition of the used phases afforded further compounds instead, $\mathrm{K}_{6}\left[\mathrm{Tl}_{2} \mathrm{Se}_{6}\right] \cdot 2 \mathrm{~K}_{2} \mathrm{CO}_{3}(6)$ and $\mathrm{K}_{0.94} \mathrm{Tl}_{0.06}\left[\mathrm{TlSe}_{2}\right]$ (7). Compound 6 again comprises dinuclear aggregates of the orthoselenidothallate anion, while 7 incorporates infinite 1D strands $\left\{\left[\mathrm{TlSe}_{2}\right]^{-}\right\}_{n}$ of corner sharing $\left[\mathrm{TlSe}_{4}\right]$ tetrahedra. So far, such chalcogenidothallate strands were only obtained as $\mathrm{K}_{x} \mathrm{Tl}_{1-x}\left[\mathrm{TlSe}_{2}\right]$ with $x<0.44,{ }^{29,30}$ but they are also known for the lighter homologues, for instance from $\mathrm{KInTe}_{2} \cdot{ }^{31}$

Only when changing the chalcogen from selenium to tellurium, and increasing the water content within the en $/ \mathrm{H}_{2} \mathrm{O}$ mixture to $3 \mathrm{vol} \%$, the first known ortho-chalcogenidothallate(III) was obtained as $\left\{\mathrm{K}_{5}\left[\mathrm{TlTe}_{4}\right] \cdot 2 \mathrm{KOH}\right\}_{3} \cdot 10 \mathrm{H}_{2} \mathrm{O}$ (8). The high water content is apparently necessary for the formation and/or crystallization of 8; replacement with $\mathrm{NH}_{3}$, for instance, did not lead to crystalline products. However, at the same time the presence of water triggers the formation of polytellurides and large amounts of amorphous side products, hence, the product had to be hand-separated from the reaction mixture.

Application of similar reaction conditions, including a $95: 5 \mathrm{en} / \mathrm{H}_{2} \mathrm{O}$ solvent mixture, to the generation of respective lead compounds resulted in the formation of a hydrate salt of the rare ortho-selenidoplumbate anion, $\mathrm{K}_{4}\left[\mathrm{PbSe}_{4}\right] \cdot \mathrm{en} \cdot \mathrm{H}_{2} \mathrm{O}(\mathbf{9})$. The structure is isostructural to the ammoniate $\mathrm{K}_{4}\left[\mathrm{PbSe}_{4}\right] \cdot$ en $\cdot \mathrm{NH}_{3}$, which was published only recently. ${ }^{11}$ The crystallographic discrimination from the ammoniate was unambiguous upon collection of a data set of very high quality (see below). Further analytical methods fail here, as both ammonia $\mathrm{N}-\mathrm{H}$ and water $\mathrm{O}-\mathrm{H}$ vibrations are overlaid by the en $\mathrm{N}-\mathrm{H}$ vibrations, and as elemental analyses tend to produce erroneous results for these heavy metal salts. The existence of a hydrate is not less amazing than the discovery of the $\left[\mathrm{PbSe}_{4}\right]^{4-}$ anion itself - the latter is anticipated to be highly 
redox active, due to the relatively poor stabilization of formal $\mathrm{Pb}$ (Iv) by selenide and furthermore supposed to be highly oxophilic. Its relative stability in the presence of $\mathrm{H}_{2} \mathrm{O}$, instead of spontaneous formation of $\left[\mathrm{PbO}_{4}\right]^{4-}$ or even spontaneous reduction, was thus unexpected. Counterintuitively again, the yield was dramatically increased from a few crystals of the ammoniate, to approx. $20 \%$ of the hydrate 9, although separation of the crystals by hand from the reaction mixture remained necessary.

Finally, we attempted solvothermal treatment of phases of the nominal composition $\mathrm{K}_{x} \mathrm{Bi}_{y} \mathrm{Se}_{z}$. Due to its thermodynamic preference, $\mathrm{K}_{3}\left[\mathrm{BiSe}_{3}\right]$ (10) was obtained from all batches. The structure was reported in the literature, however upon a rather cumbersome experimental procedure: $\mathrm{Bi}_{2} \mathrm{O}_{3}$ was reduced with $\mathrm{K}_{2}\left[\mathrm{CO}_{3}\right]$ in a selenium-charged hydrogen stream at $850{ }^{\circ} \mathrm{C} .{ }^{15}$ 10 can alternatively be obtained from simple fusion of the elements and successive work up via excessive washing with en until the filtrate turns colorless. 10 is then obtained as micro-crystalline powder in almost quantitative yields. Single crystals suitable for X-ray analysis were obtained via recrystallization by solvothermal treatment in en.

\subsection{Crystal structure description}

Crystal structure of $\mathbf{K}_{4}\left[\mathrm{HgSe}_{3}\right] \cdot \mathbf{H}_{2} \mathrm{O}$ (1). 1 crystallizes in the monoclinic space group $P 2_{1}$ with four formula units in the unit cell. The crystal features orthorhombic geometry, but monoclinic symmetry upon pseudo-merohedral twinning pretending orthorhombic symmetry. In the $\left[\mathrm{HgSe}_{3}\right]^{4-}$ anions in $\mathbf{1}$, the $\mathrm{Hg}^{2+}$ ions are coordinated by three Se atoms in a distorted trigonal planar manner (deviation from ideal Se-Hg-Se $120^{\circ}$ angles by up to $10^{\circ}$; sum of angles around central $\mathrm{Hg}$ atom $359.97^{\circ}$ ). Within the crystal structure, the anions are stabilized by $\mathrm{K}^{+}$and $\left[\mathrm{K}\left(\mu-\mathrm{H}_{2} \mathrm{O}\right) \mathrm{K}\right]^{2+}$ counter ions and thus well separated from each other (see Fig. 1).

Each $\mathrm{K}^{+}$ion is situated in a distorted octahedral environment of five Se atoms and one $\mathrm{O}$ atom, with the exception of K4 with coordination number (c.n.) 7 (see ESI†).

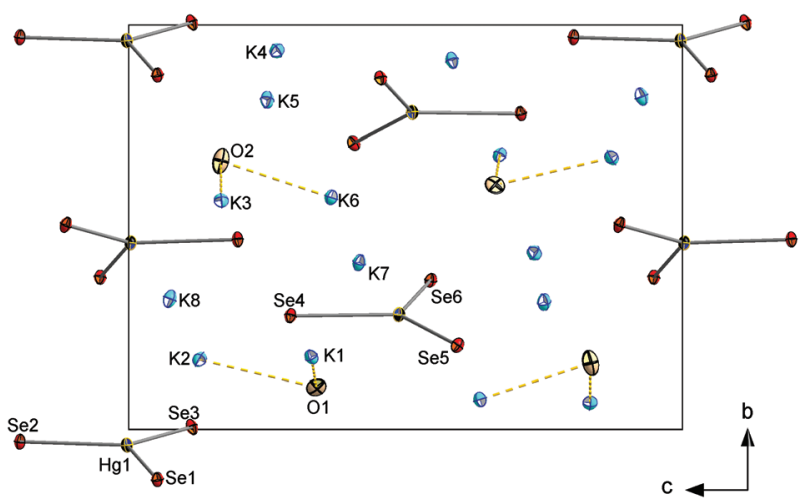

Fig. 1 Fragment of the crystal structure of 1 . Ellipsoids are drawn at $50 \%$ probability. Selected structural parameters $\left[\AA \AA{ }^{\circ}{ }^{\circ}\right]: \mathrm{Hg}-\mathrm{Se}: 2.552(2)-$

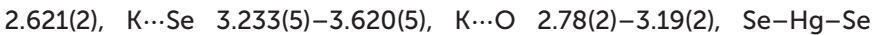
$114.02(6)-129.76(7)$

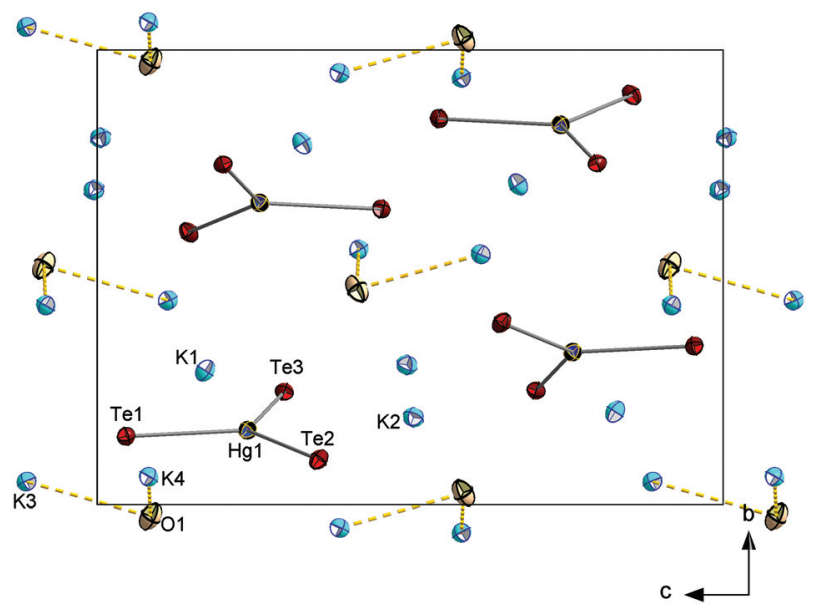

Fig. 2 Fragment of the crystal structure of 2. Ellipsoids are drawn at $50 \%$ probability. Selected structural parameters [ $\left.\AA^{\circ}{ }^{\circ}\right]$ : Hg-Te: $2.7256(6)-$

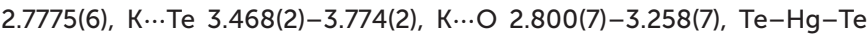
$114.427(18)-126.824(18)$.

Crystal structure of $\mathbf{K}_{4}\left[\mathrm{HgTe}_{3}\right] \cdot \mathbf{H}_{2} \mathrm{O}$ (2). 2 crystallizes in the orthorhombic space group $P 2_{1} 2_{1} 2_{1}$, a minimal non-isomorphic supergroup to that in $\mathbf{1}$, with four formula units in the unit cell. The $\left[\mathrm{HgTe}_{3}\right]^{4-}$ anions also adopt a distorted trigonal planar shape (deviation from ideal angles by approx. $6^{\circ}$, sum of angles around central $\mathrm{Hg}$ atom $359.94^{\circ}$, see Fig. 2).

$\mathrm{K}^{+}$and $\left[\mathrm{K}\left(\mu-\mathrm{H}_{2} \mathrm{O}\right) \mathrm{K}\right]^{2+}$ ions separate the anions from each other, again with distorted octahedral coordination environments of $\mathrm{K}^{+}$ions (see $\mathrm{ESI} \dagger$ ).

Crystal structure of $\mathrm{K}_{10} \mathrm{Na}_{2}\left[\mathrm{HgTe}_{3}\right]_{2}\left(\mathrm{HCO}_{2}\right)_{3}$ (3). 3 crystallizes in the monoclinic space group $C 2 / m$ with 2 formula units in the unit cell. Maximum deviation from the ideal $\mathrm{Te}-\mathrm{Hg}-\mathrm{Te}$ angle within the $\left[\mathrm{HgTe}_{3}\right]^{4-}$ anions amounts to $2^{\circ}$, the sum of angles around the central $\mathrm{Hg}$ atom is $359.98^{\circ}$. Formiate anions are linked to adjacent formiate anions in two different modes: first via one $\mathrm{K}^{+}$ion to form a nearly linear $\mathrm{O} \cdots \mathrm{K}^{+} \cdots \mathrm{O}$ connec-

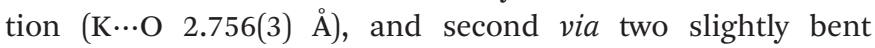

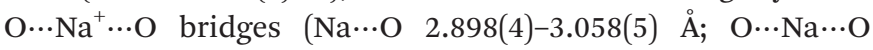
$\left.45.66(14)^{\circ}, 77.19(11)^{\circ}\right)$ and one additional $\mathrm{O} \cdots \mathrm{K}^{+} \cdots \mathrm{O}$ linkage (2.701(3)-2.854(4) $\AA$ ), see Fig. 3. This way, a complicated 3D cationic network is formed to embed well-separated $\left[\mathrm{HgTe}_{3}\right]^{2-}$ anions (see ESI†).

Crystal structure of $\mathbf{K}_{2}\left[\mathrm{HgSe}_{2}\right] \cdot \mathrm{H}_{2} \mathrm{O}$ (4). 4 crystallizes in the monoclinic space group $P 2_{1} / c$ with four formula units in the unit cell. $\mathrm{Hg}^{2+}$ ions are coordinated by three Se atoms, of which two are $\mu$-bridging to adjacent $\mathrm{Hg}^{2+}$ ions, while one is a terminal ligand. This way, $\left\{\left[\mathrm{HgSe}_{2}\right]^{2-}\right\}_{n}$ 1D anion strands are formed that extend along [001] (see Fig. 4). One of the two crystallographic independent $\mathrm{K}^{+}$ions (K4) is situated in close vicinity to its symmetry equivalent, forming a trapezoidal $\left[\mathrm{K}_{2}\left(\mu-\mathrm{H}_{2} \mathrm{O}\right)\right]^{2+}$ cation via bridging by two $\mu-\mathrm{H}_{2} \mathrm{O}$. Further saturation of the coordination sphere is achieved by three Se atoms. The second $\mathrm{K}^{+}$ion is coordinated by six Se atoms (K2, see $\mathrm{ESI} \dagger)$. 


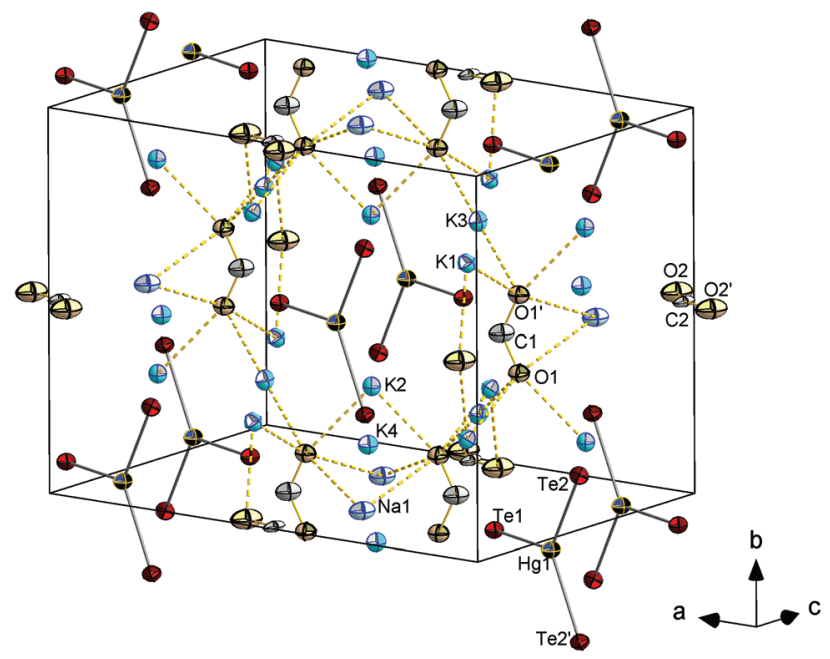

Fig. 3 Fragment of the crystal structure of 3. Ellipsoids are drawn at $50 \%$ probability. Selected structural parameters [ $\left[\AA{ }^{\circ}\right]: \mathrm{Hg}-\mathrm{Te}: 2.7397(4)-$

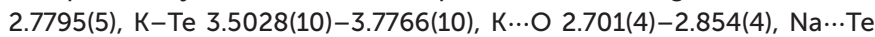
3.5342(13), Na… 2.898(4), Te-Hg-Te 119.246(8)-121.482(16).

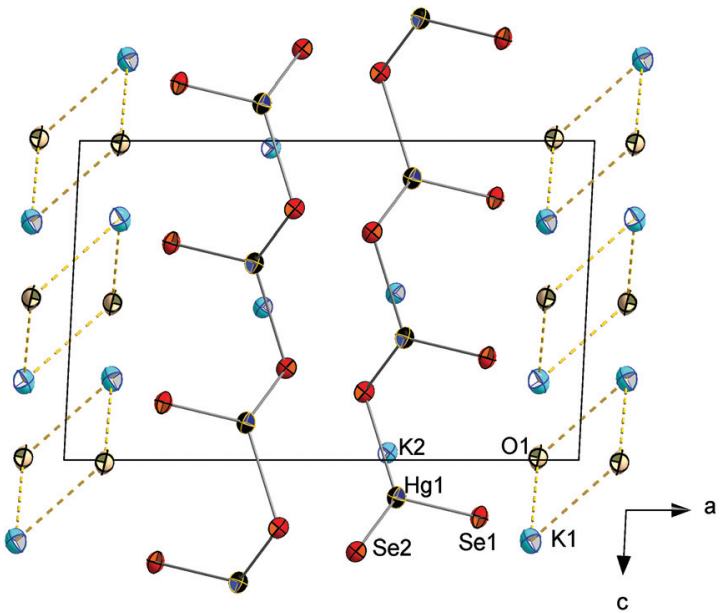

Fig. 4 Fragment of the crystal structure of 4 . Ellipsoids are drawn at $50 \%$ probability. Selected structural parameters $\left[\AA \AA{ }^{\circ}\right]: \mathrm{Hg}-\mathrm{Se} 1$ 2.5097(10), Hg-Se2 2.5908(10)-2.6090(11), K...Se 3.193(2)-3.497(2), K...O 2.789(9)-3.426(9), Se-Hg-Se 107.19(3)-132.38(3).

Crystal structure of $\mathbf{K}_{6}\left[\mathrm{Tl}_{2} \mathrm{Se}_{6}\right] \cdot 2 \mathrm{H}_{2} \mathrm{O}$ (5). 5 crystallizes in the triclinic space group $P \overline{1}$ with one formula unit in the unit cell. Each (formal) $\mathrm{Tl}^{3+}$ ion is coordinated by two terminal Se atoms and two $\mu$-bridging Se atoms, thus forming a molecular, dinuclear $\left[\mathrm{Tl}_{2} \mathrm{Se}_{6}\right]^{6-}$ anion. The anions are separated by $\mathrm{K}^{+}$ions and $\left[\mathrm{K}_{2}\left(\mu-\mathrm{H}_{2} \mathrm{O}\right)\right]^{2+}$ units (see Fig. 5 ). $\mathrm{K}^{+}$ions are each coordinated by five Se atoms and one $\mathrm{O}$ atom in a distorted octahedral fashion (see ESI†ं).

Crystal structure of $\mathrm{K}_{6}\left[\mathrm{Tl}_{2} \mathrm{Se}_{6}\right] \cdot 2 \mathrm{~K}_{2} \mathrm{CO}_{3}(6) .6$ crystallizes in the triclinic space group $P \overline{1}$ with one formula unit in the unit cell. The constitution of $\left[\mathrm{Tl}_{2} \mathrm{Se}_{6}\right]^{6-}$ anions is the same as found in 5. Carbonate ions are coordinating to eight $\mathrm{K}^{+}$ions,

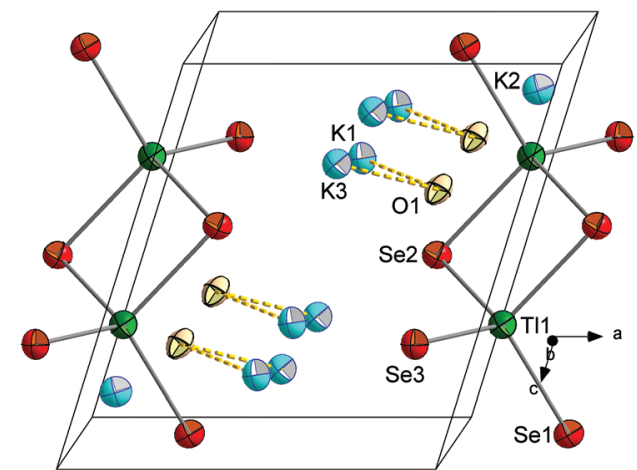

Fig. 5 Fragment of the crystal structure of 5. Ellipsoids are drawn at $50 \%$ probability. Selected structural parameters [Å, $\left.{ }^{\circ}\right]: \mathrm{Tl}-\mathrm{Se}(13)$

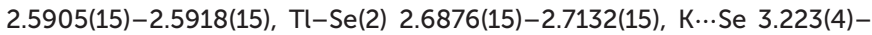
3.908(4), K ‥ 2.766(11)-2.901(12), Se(1)-Tl-Se(3) 114.53(5), Se(1,3)-Tl$\mathrm{Se}(2)$ 106.85(5)-116.66(5), Se(2)-Tl-Se(2') 96.17(4), K... O..K 96.5(3).

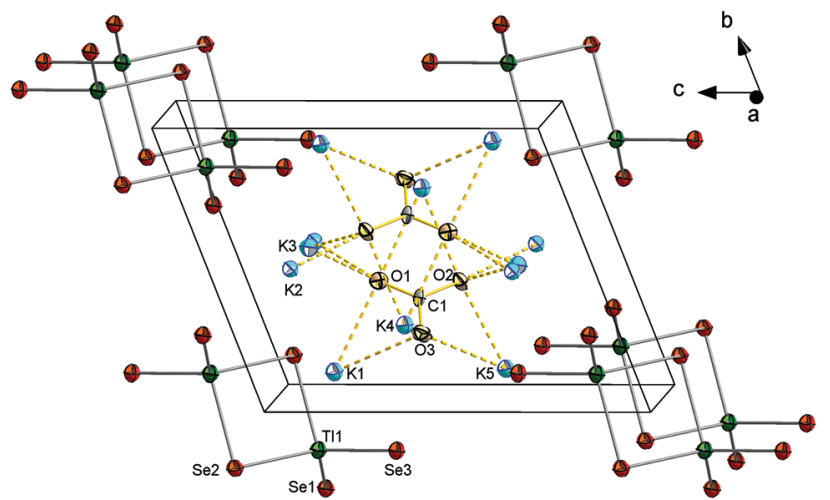

Fig. 6 Fragment of the crystal structure of 6 . Ellipsoids are drawn at $50 \%$ probability. Selected structural parameters [Å, $\left.{ }^{\circ}\right]$ : Tl-Se(1,3) $2.5824(11)-$ 2.5828(12), Tl-Se(2) 2.6629(10)-2.7273(11), K...Se 3.246(2)-3.919(3), K...O 2.681(9)-3.366(9), C-O 1.270(13)-1.327(12), Se(1)-Tl-Se(3) 115.80(3), $\mathrm{Se}(1,3)-\mathrm{Tl}-\mathrm{Se}(2)$ 103.64(4)-116.71(4), Se(2)-Tl-Se(2') 93.17(3).

three of which are chelated by the same one carbonate ion. Five further terminal $\mathrm{K}^{+}$ions, in turn, are situated between two adjacent carbonate ions to form a complicated 2D $\left[\mathrm{K}_{10}\left(\mathrm{CO}_{3}\right)_{2}\right]^{6+}$ sheet extending between layers of the anions parallel to the $a b$ plane by interconnecting strands of $\left[\mathrm{K}_{5}\left(\mathrm{CO}_{3}\right)\right]^{3+}$ along the crystallographic $a$ direction (see Fig. 6 and ESI $\dagger$ ).

Crystal structure of $\mathbf{K}_{\mathbf{0 . 9 4}} \mathbf{T l}_{\mathbf{0 . 0 6}}\left[\mathrm{TlSe}_{2}\right]$ (7). 7 crystallizes in the tetragonal space group $I 4 / \mathrm{mcm}$ with four formula units in the unit cell, being isostructural with $\mathrm{Tl}\left[\mathrm{TlSe}_{2}\right] .^{30}$ Hence, $\left[\mathrm{TlSe}_{4}\right]$ tetrahedra form 1D strands $\left\{\left[\mathrm{TlSe}_{2}\right]^{-}\right\}_{n}$ along $c$ by edge sharing (see Fig. 7). The voids between the strands accommodate the counterions, which in 7 represent a statistical mixture of $\mathrm{K}^{+}$ and $\mathrm{Tl}^{+}$ions. Refinement with free second variables results in a $94: 6$ ratio for $\mathrm{K}: \mathrm{Tl}$ on the positions.

Crystal structure of $\left\{\mathrm{K}_{5}\left[\mathrm{TITe}_{4}\right] \cdot 2 \mathrm{KOH}\right\}_{3} \cdot 10 \mathrm{H}_{2} \mathrm{O}$ (8). 8 crystallizes in the trigonal space group $R \overline{3} c$ with six formula units in 


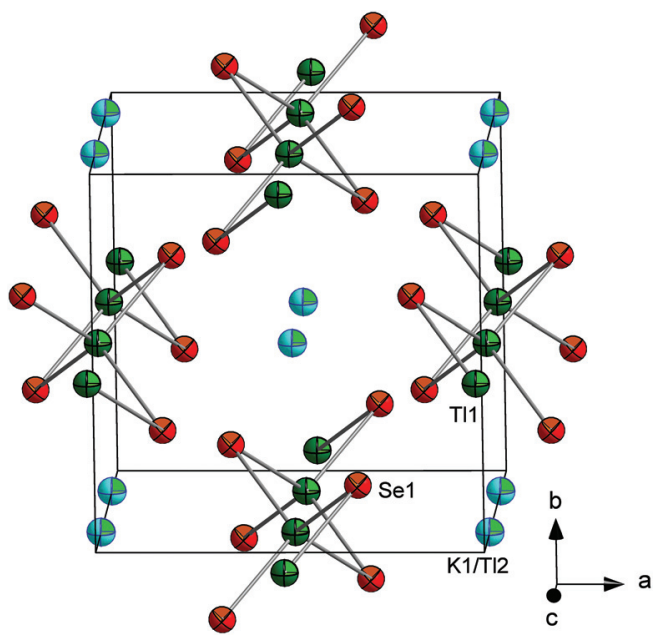

Fig. 7 Fragment of the crystal structure of 7. Ellipsoids are drawn at $50 \%$ probability. Two-colored K1/TI2 ellipsoids indicate statistical disorder on the respective positions. Selected structural parameters [ $\left[\AA{ }^{\circ}\right]$ : Tl-Se 2.6653(7), K...Se 3.4299(4), Tl-Tl 3.5052(5), Se-Tl-Se 97.77(3), 115.619(14).

the unit cell. The (formal) $\mathrm{Tl}^{3+}$ ions are surrounded by $\mathrm{Te}$ atoms in a tetrahedral mode, thus forming molecular $\left[\mathrm{TlTe}_{4}\right]^{3-}$ anions that are embedded in and separated by a complex 3D $\left\{\mathrm{K} \cdots(\mathrm{OH}) \cdots \mathrm{K} \cdots\left(\mathrm{H}_{2} \mathrm{O}\right)\right\}_{n}$ substructure (see Fig. 8). Most of the $\mathrm{K}^{+}$ ions are hexacoordinate in an octahedral manner ( $\left.\mathrm{K}_{5} \cdots \mathrm{Te}_{6}\right)$, a distorted octahedral manner $\left(\mathrm{K}_{3} \cdots \mathrm{Te}_{4} \mathrm{O}_{2}\right)$, an distorted tetrahedral $\left(\mathrm{K}_{2} \cdots \mathrm{Te}_{3} \mathrm{O}\right)$ or a trigonal prismatic manner $\left(\mathrm{K} 1 \cdots \mathrm{Te}_{3} \mathrm{O}_{3}\right)$. One of the cations is nonacoordinate $\left(\mathrm{K}_{4} \cdots \mathrm{Te}_{2} \mathrm{O}_{7}\right) . \mathrm{O}$ atoms in turn are either surrounded by $6 \mathrm{~K}^{+}$ions in a distorted octahedral fashion $(\mathrm{O} 1, \mathrm{O} 4)$ or possess a tetragonal pyramidal environment by $5 \mathrm{~K}^{+}$ions $(\mathrm{O} 2, \mathrm{O} 3)$ (see ESI $\dagger$ ). As illustrated in Fig. 8, the crystal structure of this first ortho-chalcogenidothallate salt is extreme complex, with a $c$ axis of 39.226(6) $\AA$ and a unit cell volume of $9718(2) \AA^{3}$, which is very large for an orthochalcogenidometalate salt. Maybe the steric requirements or even the electrostatic properties of the $\left[\mathrm{TlCh}_{4}\right]^{5-}$ anion impede a suitable and efficient packing of alkali(ne earth) metal cations along with the anions; hence, co-crystallization with two formula units of $\mathrm{KOH}$ might be essential, however leading to the shown structural complexity.

Crystal structure of $\mathrm{K}_{\mathbf{4}}\left[\mathrm{PbSe}_{\mathbf{4}}\right] \cdot \mathbf{e n} \cdot \mathrm{H}_{2} \mathrm{O}$ (9). 9 crystallizes in triclinic space group $P \overline{1}$ with two formula units in the unit cell. Compound 9 is isostructural with $\mathrm{K}_{4}\left[\mathrm{PbSe}_{4}\right] \cdot \mathrm{en} \cdot \mathrm{NH}_{3} \cdot{ }^{11}$ The presence of water instead of ammonia was unambiguously confirmed by structure solution and refinement using a very precise data set: the refinement of nitrogen atoms on the respective positions led to not positive-defined displacement parameters; furthermore, the two hydrogen atoms per water molecule were localized on the difference Fourier map and refined freely. Thus, 9 indeed represents the second known ortho-chalcogenidoplumbate(Iv) salt (see Fig. 9). Bond lengths and angles are in good agreement with the reported structure parameters of the ammoniate.

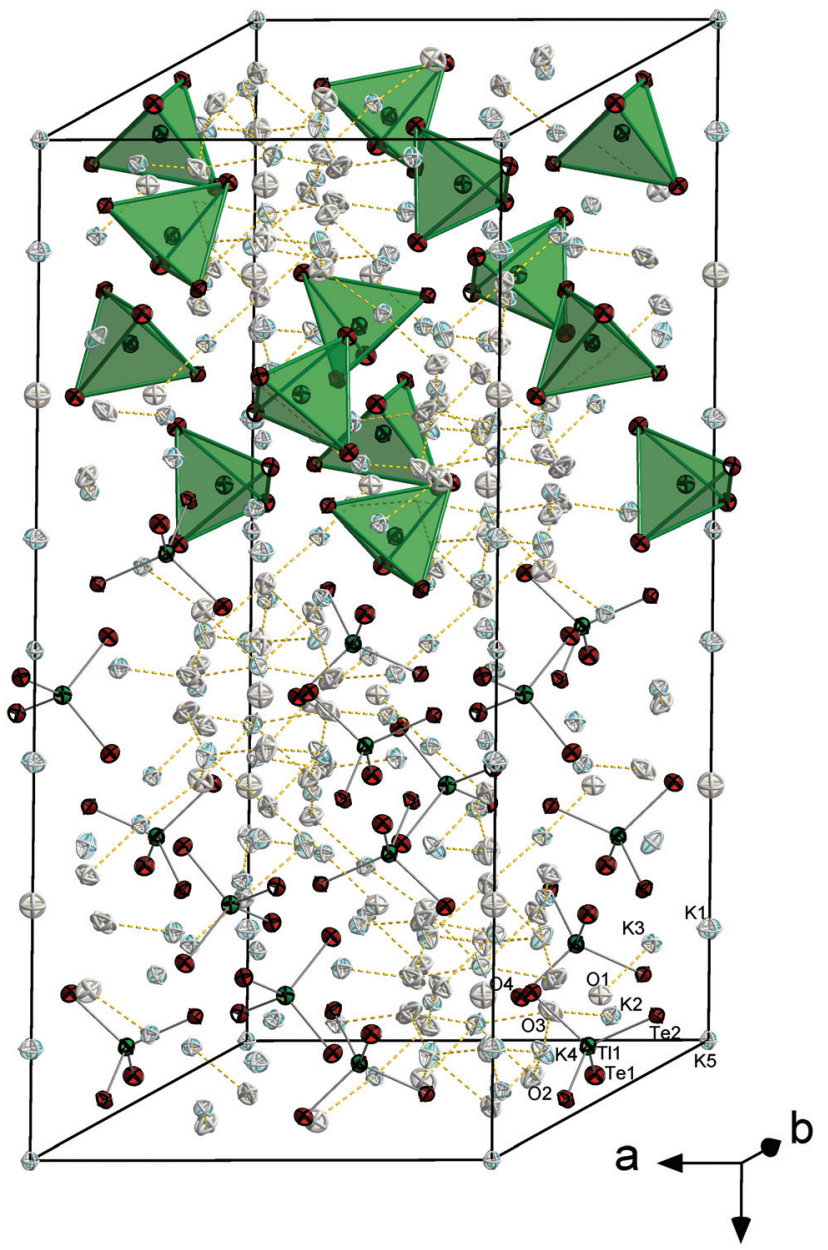

Fig. 8 Fragment of the crystal structure of 8 . Ellipsoids are drawn at $50 \%$ probability. $\mathrm{K}$ and $\mathrm{O}$ atoms are drawn in opaque mode, and some of the tetrahedral anions are shown as polyhedra for clarity. Selected structural parameters $\left[\AA \AA{ }^{\circ}\right]$ : Tl-Te 2.8386(12)-2.8458(13), K...Te 3.537(4)3.916(5), K … 2.753(15)-3.053(6), Te-Tl-Te 107.26(3)-122.43(3).

\subsection{Quantum chemical calculations}

The compounds presented above served to fill some of the existing gaps in the spectrum of known mononuclear or dinuclear chalcogenidometalate anions of the heaviest metals (see Table 1 below). However, many combinations have still not been observed experimentally. We were thus interested, whether according, yet missing species are (a) local minima on the respective energy hypersurfaces, and whether they are (b) accessible via chemical reactions in principle.

This might then allow for recommendations for future synthetic approaches: in the case of endoenergetic reactions, classical solid state reaction would more likely be successful, while in the case of an exoenergetic reaction, a reaction in solution should in principle be also possible or even preferred.

In a first step, we simultaneously optimized electronic and geometric structures of all mononuclear anions (meta and ortho type) and the pseudo-dimeric ones by means of DFT calculations, followed by the determination of second derivatives 


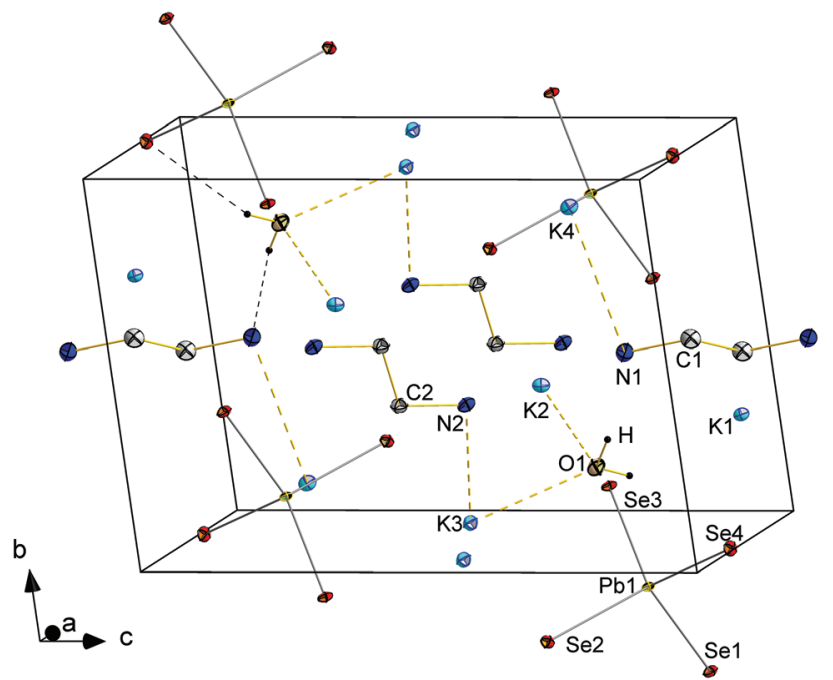

Fig. 9 Fragment of the crystal structure of 9. Ellipsoids are drawn at $50 \%$ probability. $\mathrm{H}$ atoms are omitted for clarity. Selected structural

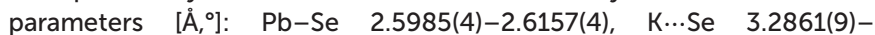

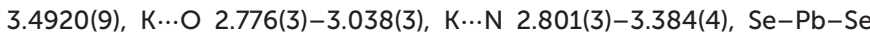
$107.02(2)-110.94(2)$.

of the energy to verify the local minimum character of the shown anions on the energy hypersurface (non-minimum structures to be found in the ESI†). In a second step, we compared the energies of the respective anions and potential elimination products to calculate hypothetic reaction energies.

The accuracy of the calculated structures are within the expected range, i.e., bond lengths by a maximum of $0.067 \AA$ larger than experimentally found ones. Hence, the chosen method is reliable enough for investigation of reaction energies.

It should be noted that the energy values that result upon application of COSMO are afflicted with systematic errors. This is due to a mismatch of gradient and absolute energy conver- gence in all cases, and even more pronounced if the numbers and/or charges of educts and products differ. Still, the errors are comparably small compared to the errors that are made during calculations of anions without the use of COSMO. In the present case, the errors are identical or at least very similar for all calculations as all species are highly related, such that a discussion of relative energies is reasonable. Furthermore, for the calculations, we chose appropriate reactants to account for the named problems with the quantum chemical treatment of anions: by using $\mathrm{H}_{2} \mathrm{Se}$ and (HSe) ${ }^{-}$for balancing the number of selenium ions (instead of $\mathrm{Se}^{2-}$ ), and by the choice of synthesis steps that do not require the consideration of naked metal cations $\mathrm{Hg}^{2+}, \mathrm{Tl}^{1 / 3+}, \mathrm{Pb}^{2 / 4+}$, or $\mathrm{Bi}^{3 / 5+}$ we cared for a minimum of charges and charge differences to be dealt with. The results are presented in the following, on the example of the respective selenides.

Mercurates. Including our own contributions of the synthesis of 1-3, three mononuclear chalcogenidomercurate anions have been experimentally observed so far: $\left[\mathrm{HgCh}_{4}\right]^{6-}$, $\left[\mathrm{HgCh}_{3}\right]^{4-}$, and $\left[\mathrm{HgSe}_{2}\right]^{2-}$. However, attempts to generate the so far unknown $\left[\mathrm{Hg}_{2} \mathrm{Ch}_{3}\right]^{2-}$ anion, in analogy to $\left[\mathrm{Pb}_{2} \mathrm{Ch}_{3}\right]^{2-}$ (ref. 13) by in situ reduction of chalcogen-rich metalchalcogenides with alkali metals in solution ${ }^{15}$ have not succeeded, but led to the formation of the well-known, linear $\left[\mathrm{HgCh}_{2}\right]^{2-}$ anions $^{9}$ in all cases. This could be rationalized by the calculations illustrated in Scheme 1.

Starting out from the ortho-mercurate anion in a hypothetical transformation pathway through the mononuclear metamercurate towards the linear $\left[\mathrm{HgSe}_{2}\right]^{2-}$ anion under release of an $\mathrm{Se}^{2-}$ ligand in each step (considered as $(\mathrm{HSe})^{-}$for the reasons given above), both reaction steps are exoenergetic. This is in line with the synthesis of $\left[\mathrm{HgCh}_{2}\right]^{2-}$ from solution and $\left[\mathrm{HgCh}_{4}\right]^{6-}$ from solid state reactions, and does not contradict an access of the molecular meta-mercurate under solvothermal conditions. Starting from a hypothetical $\left[\mathrm{Hg}_{2} \mathrm{Se}_{3}\right]^{2-}$ anion in a reverse reaction scheme produces two equivalents of the linear $\left[\mathrm{HgSe}_{2}\right]^{2-}$, again in an exoenergetic reaction.

Table 1 Overview of previously known $(x)$ or newly synthesized $(\checkmark)$ mononuclear selenidometalates or telluridometalates of $\mathrm{Hg}, \mathrm{Tl}$, $\mathrm{Pb}$, or $\mathrm{Bi}$ as central atoms. Both signs together indicate significant additions to a known species (see text). Empty boxes indicate so far unknown species. Circles or dashes, respectively, indicate whether the calculated structures of the selenides represent local minima on the energy hypersurfaces or not (or did not converge at all). According tellurides have not been calculated in this study

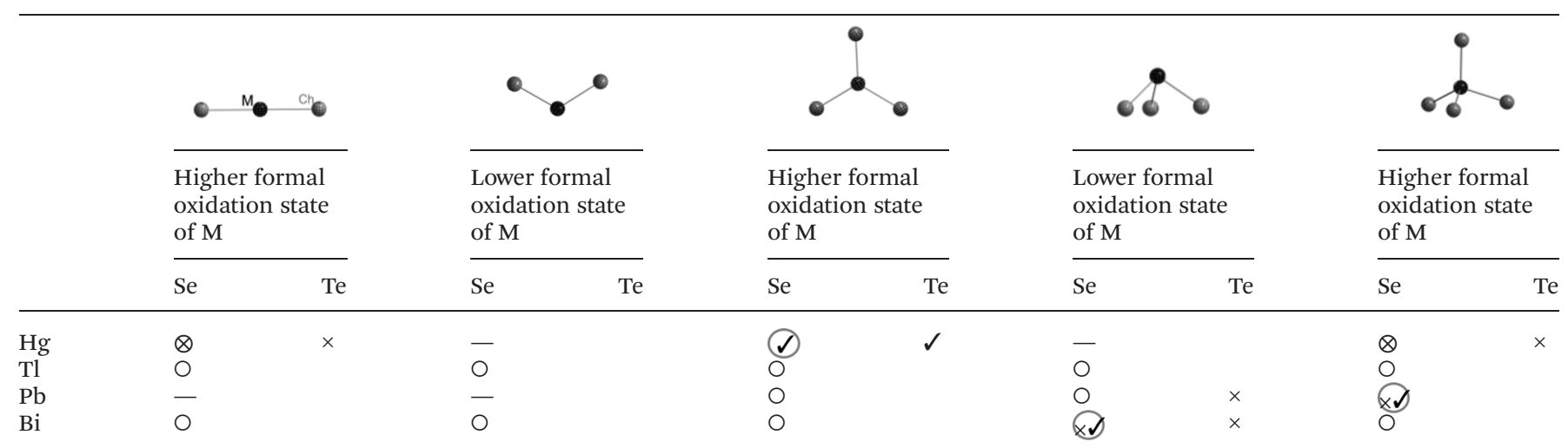




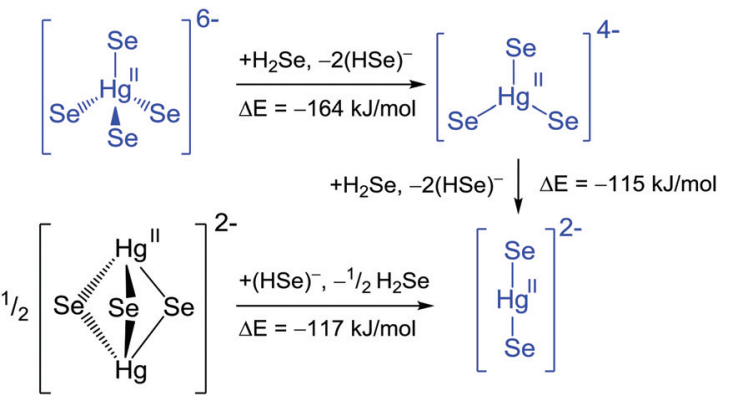

Scheme 1 Reaction pathways and energies for the transformation of chalcogenidomercurates. Blue colour indicates experimentally observed anions.

Thus, although $\left[\mathrm{Hg}_{2} \mathrm{Se}_{3}\right]^{2-}$ is a minimum on the energy hypersurface, it becomes obvious, why no such species has been reported so far: in solution the transformation towards $\left[\mathrm{HgSe}_{2}\right]^{2-}$ is expected, while a solid state reaction employing the respective $2: 2: 3$ stoichiometric ratio rather produces an extended mercurate framework structure, such as $\mathrm{K}_{2} \mathrm{Hg}_{2} \mathrm{Se}_{3} .{ }^{25}$ Obviously, this structure type is not available for the $6: 1: 4$ ratio, hence solid state reactions allow for the isolation of the tetrahedral $\left[\mathrm{HgSe}_{4}\right]^{6-}$ subunit. A comparison of the $\mathrm{Hg}-\mathrm{Se}$ bond lengths for the planar $\left[\mathrm{HgSe}_{3}\right]^{4-}(2.64 \AA)$ versus $\left[\mathrm{HgSe}_{3}\right]^{5-}$ (3.01 $\AA$ ) is in agreement with the formal +II oxidation state at the $\mathrm{Hg}$ atoms in 1-3.

To the best of our knowledge, no chalcogenidomercurate(I) anion has been characterized so far. Nevertheless, we calculated the corresponding anions $\left[\mathrm{Hg}_{2} \mathrm{Se}_{3}\right]^{4-}$ (trigonal bipyramidal) and $\left[\mathrm{HgSe}_{3}\right]^{5-}$ (trigonal planar or pyramidal). The trigonal bipyramidal anion does not converge into a reasonable structure. The meta-mercurate(I) is a minimum on the energy hypersurface in the planar and the pyramidal conformation, with the latter being favoured, but both compounds are open shell systems, which is expected to hamper their isolation.

Thallates. The situation for chalcogenidothallates is somewhat more complex in terms of the availability of different oxidation state. Both, $+_{\mathrm{I}}$ and ${ }_{\mathrm{IIII}}$, are known within experimentally observed metalate anions, as ortho-chalcogenidothallate(III) anion $\left[\mathrm{TlCh}_{4}\right]^{5-}(5-8)$ and the butterfly-like chalcogenidothallate(I) anion $\left[\mathrm{Tl}_{2} \mathrm{Ch}_{2}\right]^{2-}$. However, as shown in Scheme 2, even more of the small anions turned out to be minima on the energy hypersurface.

Hypothetic reaction cascades starting out from the orthothallate anion through a molecular meta-thallate anion $\left[\mathrm{TlSe}_{3}\right]^{3-}$ and further on to a linear $\left[\mathrm{TlSe}_{2}\right]^{-}$anion are exoenergetic, but especially the second step is only slightly exoenergetic. Principally, the existence of the respective species under the simulated conditions should hence be possible. However, this pathway is obviously excelled by the shown and observed dimerization, which is even more exoenergetic. A possible redox reaction yielding a pyramidal $\left[\mathrm{TlSe}_{3}\right]^{5-}$ anion is energetically highly disfavoured, such that the exoenergetic step to the bent $\left[\mathrm{TlSe}_{2}\right]^{3-}$ species is not achievable this way. Thus, it

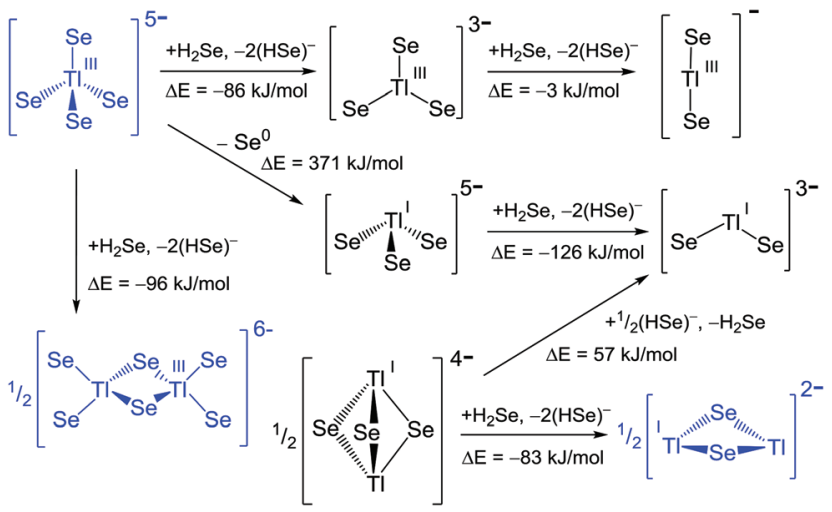

Scheme 2 Reaction pathways and energies for the transformation of selenido-thallates. Blue colour indicates experimentally observed anions.

becomes perspicuous why an interconversion between thallate(III) and thallate(I) anions have not yet been observed. Regarding the possible thallate $(\mathrm{I})$ species, both $\left[\mathrm{TlSe}_{2}\right]^{3-}$ and the butterfly-like $\left[\mathrm{Tl}_{2} \mathrm{Se}_{2}\right]^{2-}$ anion should be accessible from an energetic point of view starting out from a (hypothetical) $\left[\mathrm{Tl}_{2} \mathrm{Se}_{3}\right]^{4-}$ bipyramid, but only the second was observed so far. Neither Schrobilgen's comprehensive NMR studies on such systems, ${ }^{10}$ nor our own attempts ${ }^{16}$ have so far yielded any indication of further thallate(I) anions. However, a related compound, $\left[\mathrm{TlTe}_{3} \mathrm{~Pb}\right]^{3-},{ }^{12 b}$ was published, hence further extension and variations of the synthetic approached should eventually allow for the synthesis of the other species, maybe even by the use of the quoted ternary anion.

Plumbates. As for the lighter homologues, the only possible mononuclear chalcogenidoplumbates are those given in Scheme 3 , besides $\left[\mathrm{Pb}_{2} \mathrm{Ch}_{3}\right]^{2-}$. Reaction energies for transformations starting from $\left[\mathrm{Pb}_{2} \mathrm{Ch}_{3}\right]^{2-}$, however, require the elimination of $\mathrm{Pb}^{2+}$ or the simulation of PbSe formation, both of which are not feasible with the methods used here (see also above). Bent $\left[\mathrm{PbCh}_{2}\right]^{2-}$, as found in the anionic $\mathrm{Tl} / \mathrm{Ch}$ system, possess two imaginary vibrational modes, thus does not represent a minimum on the energy hypersurface.

The degradation of ortho-selenidoplumbate(rv) anion towards a carbonate homologue under release of a selenide ligand is not associated with a significant energy change,

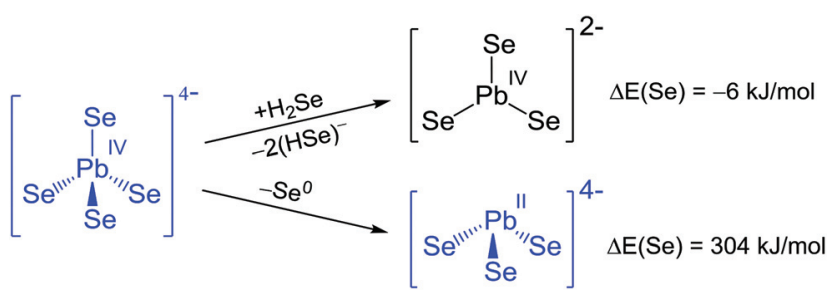

Scheme 3 Reaction pathways and energies for the transformation of selenidoplumbates. Blue colour indicates experimentally observed anions, however, in the case of the $\left[\mathrm{PbCh}_{3}\right]^{2-}$ anion, only the tellurium analogue has been isolated so far. 
hence differences either considering a solvent shell or a counterion environment may easily overcompensate it to an overall preference of the tetrahedral anion. An oxidative elimination of selenium to form the pyramidal $\left[\mathrm{PbSe}_{3}\right]^{4-}$ anion is considerably endoenergetic, apparently contradicting the experimental observation of the meta-telluridoplumbate(II), but in agreement with a synthesis starting out from a $\mathrm{Pb}(\mathrm{II})$ precursor and thus avoiding the disfavoured redox reaction step. Moreover, the distinct energetic preference of the ortho-selenidoplumbate(Iv) over its dissociation or dechalcogenation is in line with its formation in and crystallization from solution, even as a hydrate like 9.

Bismuthates. For chalcogenidobismuthates, the list of experimentally observed anions is the smallest along the elemental combinations investigated in the current study. However, the list of hypothetical anions comprises four minima on the energy hypersurface (see Scheme 4). Further minima on the energy hypersurface with intriguing electronic features are the neutral trigonal bipyramidal $\mathrm{Bi}_{2} \mathrm{Ch}_{3}$, which however rather exist as the extended solid state compounds paraguanajuatite $^{32}$ or tellurobismuthite, ${ }^{33}$ and two chalcogenbismuth cations $\left[\mathrm{Bi}_{2} \mathrm{Ch}_{2}\right]^{2+}$ with butterfly-like geometry and linear $\left[\mathrm{BiCh}_{2}\right]^{+}$. For the reasons given above, these shall not be discussed in the context of chalcogenidometalate anion chemistry.

All reactions starting from a hypothetic ortho-bismuthate(v) anion including stepwise elimination and/or dissociation of $\mathrm{Se}^{0} / \mathrm{Se}^{2-}$ are endoenergetic. Thus the existence of $\left[\mathrm{BiSe}_{4}\right]^{3-}$ does not seem to be generally unrealistic. However, very obviously, so far only chalcogenidobismuthates of $\mathrm{Bi}$ (III) have been produced that seem to be kinetically stable enough not to undergo the hypothetic, exoenergetic oxidation towards the tetrahedral species. $\left[\mathrm{BiSe}_{3}\right]^{-}$would be the second heaviest possible homologue of the nitrate $\left[\mathrm{NO}_{3}\right]^{-}$anion, yet its formation is not favourable according to energetic considerations. Also a bent $\left[\mathrm{BiSe}_{2}\right]^{-}$species represents a minimum on the energy hypersurface, yet its formation from the observed $\left[\mathrm{BiSe}_{3}\right]^{3-}$ anion would require another $21 \mathrm{~kJ} \mathrm{~mol}^{-1}$. For this, although not isolated yet, the list of potentially observable $\mathrm{Bi}$ / Se anions definitely include the homologues of $\left[\mathrm{NO}_{3}\right]^{-},\left[\mathrm{PO}_{4}\right]^{3-}$ and $\left[\mathrm{NO}_{2}\right]^{-}$in addition to the observed $\left[\mathrm{BiCh}_{3}\right]^{3-}$ anions. The

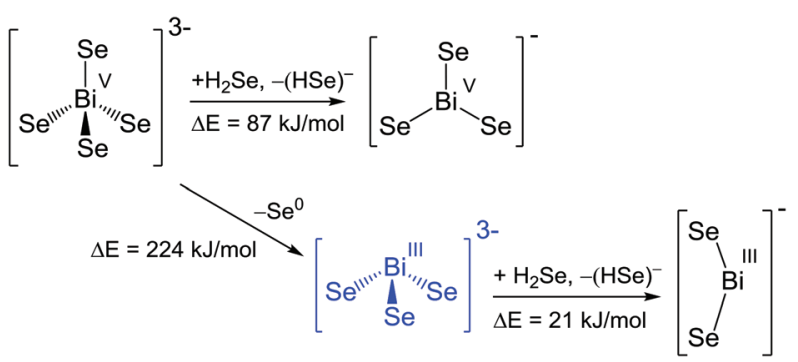

Scheme 4 Reaction pathways and energies for the transformation of selenidobismuthates. Blue colour indicates experimentally observed anions.
Table 2 Overview of previously known $(x)$ or newly synthesized $(\checkmark)$ dinuclear selenidometalates or telluridometalates of $\mathrm{Hg}, \mathrm{Tl}, \mathrm{Pb}$, or $\mathrm{Bi}$ as central atoms. Empty boxes indicate so far unknown species. Circles indicate that the calculated structures of the selenides represent local minima on the energy hypersurfaces. The entry $n / a$ indicates that an according species was not considered as it would be either neutral or cationic. According tellurides have not been calculated in this study

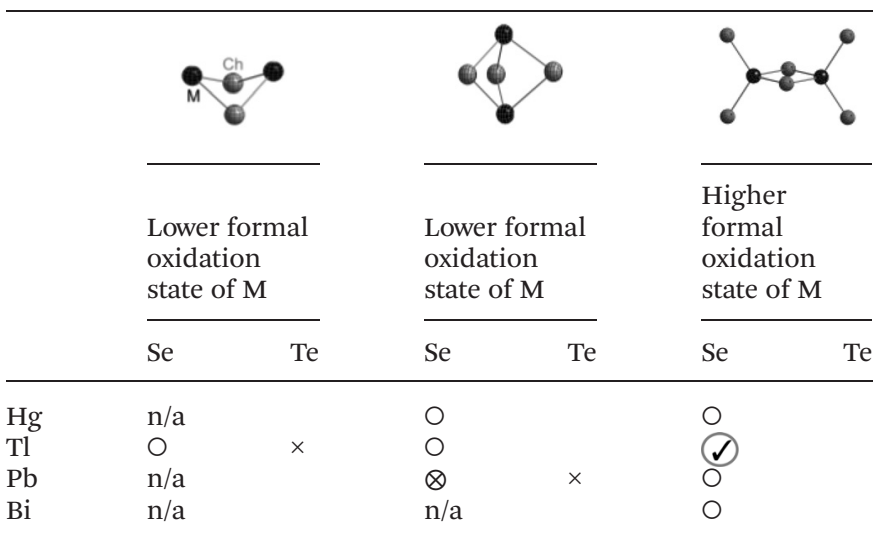

remaining challenge is finding an appropriate synthetic approach, such as described recently and once more herein for salts of $\left[\mathrm{PbSe}_{4}\right]^{4-}$.

\section{Conclusions}

We presented the synthesis and structure of novel ortho- and meta-chalcogenidometalates of mercury, thallium and lead, including the first molecular meta-chalcogenidomercurate(II), the first ortho-chalcogenidothallate(III) and the second orthoselenidoplumbate(Iv). The latter emerged for the first time and unexpectedly as its hydrate salt. In addition, we reported a new and facile synthetic pathway for the generation of the metaselenidobismuthate in almost quantitative yield. The existence of all those anions inspired quantum chemical investigations of structures and energetics of the diverse species with different elemental combinations. We discussed hypothetic reaction energies, which helped to rationalize the observations and to predict further species to be isolated in future work. In the case of the chalcogenidoplumbates, the heaviest $\left[\mathrm{CO}_{3}\right]^{2-}$ homologues are generally stable, however most likely not accessible via solution based techniques. The same is valid for the chalcogenidobismuthate homologues of $\left[\mathrm{NO}_{3}\right]^{-}$. Tables 1 and 2 summarize the experimental and theoretical findings for all smallest molecular chalcogenidometalate anions of the heaviest metals, including the new ones.

\section{Acknowledgements}

We are indebted to Jörn Münzer and Marcus Müller for their help with synthetic work. We gratefully acknowledge fruitful discussion with Prof. Dr Werner Massa on the structure refinement of compound 9. This work was supported by the 
Deutsche Forschungsgemeinschaft (DFG) within the framework of SPP 1415. GT thanks for financial support by the Friedrich-Ebert-Stiftung (FES).

\section{References}

1 C. D. Morris, H. Li, H. Jin, C. D. Malliakas, J. A. Peters, P. N. Trikalitis, A. J. Freeman, B. W. Wessels and M. G. Kanatzidis, Chem. Mater., 2013, 25, 3344.

2 M. A. McGuire, T. J. Scheidemantel, J. V. Badding and F. J. DiSalvo, Chem. Mater., 2005, 17, 6186.

3 (a) S. Wagner, J. L. Shay, P. Migliorato and H. M. Kasper, Appl. Phys. Lett., 1974, 25, 434; (b) M. G. Panthani, V. Akhavan, B. Goodfellow, J. P. Schmidtke, L. Dunn, A. Dobabalapur, P. F. Barbara and B. A. Korgel, J. Am. Chem. Soc., 1998, 120, 16770.

4 J. Androulakis, S. C. Peter, H. Li, C. D. Malliakas, J. A. Peters, Z. Liu, B. W. Wessels, J.-H. Song, H. Jin, A. J. Freeman and M. G. Kanatzidis, Adv. Mater., 2011, 23, 4163.

5 (a) F. Lips and S. Dehnen, Inorg. Chem., 2008, 47, 5561; (b) E. Ruzin, E. Zent, E. Matern, W. Massa and S. Dehnen, Chem. - Eur. J., 2009, 15, 5230.

6 (a) J. Heine and S. Dehnen, Z. Anorg. Allg. Chem., 2012, 638, 2425; (b) S. Dehnen and M. Melullis, Coord. Chem. Rev., 2007, 251, 1259; (c) E. Ruzin, A. Fuchs and S. Dehnen, Chem. Commun., 2006, 4796; (d) E. Ruzin and S. Dehnen, Z. Anorg. Allg. Chem., 2006, 632, 749; (e) S. Dehnen and M. K. Brandmayer, J. Am. Chem. Soc., 2003, 125, 6618.

7 (a) W. S. Sheldrick, in Handbook of Chalcogen Chemistry, ed. F. Devillanova, The Royal Society of Chemistry, London, 2007, ch 9.2; (b) W. S. Sheldrick and M. Wachhold, Angew. Chem., Int. Ed. Engl., 1997, 36, 206; (c) M. G. Kanatzidis and S.-P. Huang, Coord. Chem. Rev., 1994, 130, 509; (d) M. A. Ansari and J. A. Ibers, Coord. Chem. Rev., 1990, 100, 223.

8 H. Sommer and R. Hoppe, Z. Anorg. Allg. Chem., 1978, 443, 201.

9 C.-W. Park, D. M. Smith, M. A. Pell and J. A. Ibers, Inorg. Chem., 1997, 36, 942.

10 (a) R. C. Burns and J. D. Corbett, J. Am. Chem. Soc., 1981, 103, 2627; (b) H. Borrmann, J. Campbell, D. A. Dixon, H. P. A. Mercier, A. M. Pirani and G. J. Schrobilgen, Inorg. Chem., 1998, 37, 1929.

11 G. Thiele, T. Krüger and S. Dehnen, Angew. Chem., Int. Ed., 2014, 53, 4699.

12 (a) M. Björgvinsson, J. F. Sawyer and G. J. Schrobilgen, Inorg. Chem., 1987, 26, 741; (b) H. Borrmann, J. Campbell, D. A. Dixon, H. P. A. Mercier, A. M. Pirani and G. J. Schrobilgen, Inorg. Chem., 1998, 37, 6656; (c) M. Björgvinsson, J. F. Sawyer and G. J. Schrobilgen, Inorg. Chem., 1991, 30, 2231; (d) C.-W. Park, R. J. Salm and J. A. Ibers, Can. J. Chem., 1995, 73, 1148.

13 C. D. W. Jones, F. J. DiSalvo and R. C. Haushalter, Inorg. Chem., 1998, 37, 821.
14 (a) W. Bronger, A. Donike and D. Schmitz, Z. Anorg. Allg. Chem., 1996, 622, 1003; (b) B. Eisenmann and R. Zagler, $Z$. Kristallogr., 1991, 197, 257.

15 G. Thiele, L. Vondung and S. Dehnen, Z. Anorg. Allg. Chem., 2015, 641, 247.

16 (a) L. Protesescu, M. Nachtegaal, O. Voznyy, O. Borovinskaya, A. J. Rossini, L. Emsley, C. Copéret, D. Günther, E. H. Sargent and M. V. Kovalenko, J. Am. Chem. Soc., 2015, 137, 1862; (b) E. Ruzin, A. Fuchs and S. Dehnen, Chem. Commun., 2006, 4796; (c) M. W. DeGroot, H. Rösner and J. F. Corrigan, Chem. - Eur. J., 2006, 12, 1547; (d) M. Melullis, R. Clérac and S. Dehnen, Chem. Commun., 2005, 6008; (e) C. Zimmermann, C. E. Anson, F. Weigend, R. Clérac and S. Dehnen, Inorg. Chem., 2005, 44, 5686; (f) M. K. Brandmayer, R. Clérac, F. Weigend and S. Dehnen, Chem. - Eur. J., 2004, 10, 5147; (g) C. Zimmermann, M. Melullis and S. Dehnen, Angew. Chem., Int. Ed., 2002, 41, 4269.

17 Turbomole Version 6.6, Turbomole GmbH 2014, Turbomole is a development of University of Karlsruhe and Forschungszentrum Karlsruhe 1989-2007, Turbomole GmbH since 2007; (a) F. Furche, R. Ahlrichs, C. Hättig, W. Klopper, M. Sierka and F. Weigend, WIREs Comput. Mol. Sci., 2014, 4, 91; (b) F. Weigend, Phys. Chem. Chem. Phys., 2006, 8, 1057.

18 A. Klamt and G. Schüürmann, J. Chem. Soc., Perkin Trans. 2, 1993, 799.

19 (a) D. Becke, Phys. Rev. A, 1988, 38, 3098; (b) J. P. Perdew, Phys. Rev. B: Condens. Matter, 1986, 33, 8822.

20 (a) F. Weigend and R. Ahlrichs, Phys. Chem. Chem. Phys., 2005, 7, 3297; (b) F. Weigend, Phys. Chem. Chem. Phys., 2006, 8, 1057; (c) M. Dolg, H. Stoll, A. Savin and H. Preuss, Theor. Chim. Acta, 1989, 75, 173; (d) H. Stoll, B. Metz and M. Dolg, J. Comput. Chem., 2002, 23, 767.

21 (a) J. Heine and S. Dehnen, Z. Anorg. Allg. Chem., 2008, 634, 2303; (b) E. Ruzin, S. Jakobi and S. Dehnen, Z. Anorg. Allg. Chem., 2008, 634, 995.

22 G. Thiele, L. Vondung, C. Donsbach, S. Pulz and S. Dehnen, Z. Anorg. Allg. Chem., 2014, 640, 2684.

23 G. Thiele, L. Vondung and S. Dehnen, unpublished results. 24 M. G. Kanatzidis and Y. Park, Chem. Mater., 1990, 2, 99.

25 G. Thiele, S. Lippert, F. Fahrnbauer, P. Bron, O. Oeckler, A. Rahimi-Iman, M. Koch, B. Roling and S. Dehnen, Chem. Mater., 2015, 27, 4114.

26 P. Boettcher, J. Getzschmann and R. Keller, Z. Anorg. Allg. Chem., 1993, 619, 476.

27 B. Eisenmann and H. Schaefer, Angew. Chem., Int. Ed. Engl., 1978, 90, 731.

28 P. Feng, X. Bu and N. Zheng, Acc. Chem. Res., 2005, 38, 293. 29 J. Weis, R. Schäfer and G. Schön, Z. Naturforsch., B: Anorg. Chem. Org. Chem., 1976, 31, 1336.

30 J. A. A. Ketelaar, W. H. t'Hart and D. Polder, Z. Kristallogr., 1939, 101, 396.

31 E. R. Franke and H. Schäfer, Z. Naturforsch., B: Anorg. Chem. Org. Chem. Biochem. Biophys. Biol., 1972, 27, 1308.

32 E. Dönges, Z. Anorg. Allg. Chem., 1951, 265, 56.

33 P. W. Lange, Naturwissenschaften, 1939, 27, 133. 